\title{
Fatores intervenientes na mediação pedagógica do tutor: o caso de um curso de graduação em administração pública PNAP/UAB
}

\section{Factores que intervienen en la mediación pedagógica del tutor: el caso de un curso de grado en administración pública PNAP/UAB}

DOI: $10.46814 / \operatorname{lajdv} 3 \mathrm{n} 5-012$

Recebimento dos originais: 01/07/2021

Aceitação para publicação: 31/08/2021

\author{
Maria Aparecida de Araújo Lima \\ Doutoranda em Educação \\ Mestra em Educação \\ Universidade de Salamanca (USAL) - ES \\ Instituto Politécnico de Bragança (IPB) - PT \\ Universidade Aberta do Brasil (UAB) - BR \\ Avenida Sá Carneiro n 3224 drt - 5300-252 Bragança - Portugal \\ E-mail: cidaaraujo.uab@gmail.com
}

Eliana M. Oliveira Sá

Mestra em Educação

Federação das Indústrias do Estado de Alagoas (FIEA) - IEL/AL- BR

Faculdade da Cidade de Maceió (FACIMA) - BR

Faculdade da Sociedade de Ensino Universitário do Nordeste (SEUNE) - BR

Rua Industrial Aloísio Nogueira, 155 - J. Petrópolis CEP 57.080-790 - Maceió/AL - Brasil

elianasa2010@gmail.com

Ana García-Valcárcel Muñoz-Repiso

Doctora en Ciencias de la Educación

Universidad de Salamanca

Paseo de Canalejas, 168. 37008 Salamanca - Espanha

E-mail: anagv@usal.es

\section{Manuel Florindo Alves Meirinhos}

Doutor

Instituto Politécnico de Bragança (IPB) - Portugal

Escola Superior de Educação de Bragança (IPB)

Campus de Santa Apolónia - 5300-253 Bragança- Portugal

E-mail: meirinhos@ipb.pt

\section{RESUMO}

Este estudo apresenta os resultados de uma pesquisa qualitativa sobre fatores intervenientes na mediação pedagógica do tutor: o caso de um curso de Bacharelado em Administração Pública a distância (ADMP) do PNAP, ofertado por meiodo Sistema UAB, em uma universidade pública da região Nordeste, iniciado em 2009. A questão norteadora foi: existem fatores que interferem na mediação pedagógica do tutor online? O objetivo foi identificar os fatores intervenientes e as múltiplas determinações que interferem na mediação pedagógica do tutor. A coleta de dados foi realizada por meio de questionário e de entrevista com os tutores online. Também foram observadas mensagens 


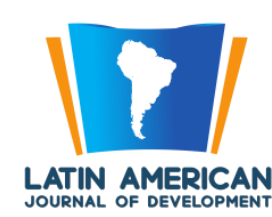

postadas no Ambiente Virtual de Aprendizagem (AVA). Participaram da pesquisa 11 tutores online, de um universo de 17 tutores que realizaram mediação pedagógica no curso pesquisado, entre $2012 \mathrm{e}$ 2013. O resultado da pesquisa indica que fatores relacionados à qualidade do ensino; à qualidade dos materiais didáticos e materiais de apoio ao aluno; ao AVA; à infraestrutura física, tecnológica e administrativa disponível para os alunos e o grau de aproximação entre o professor e tutor interferem no desempenho do tutor online que atua no processo de ensino-estudo-aprendizagem do aluno da EAD ofertada com o uso da internet. Convém informar que o conteúdo deste artigo foi discutido em várias ocasiões em 2014 e 2015. Porém torna-se relevante retomar a discussão no campo da EAD devido ao momento pandêmico, no qual a mediação pedagógica foi intensificada, pelo fato das aulas presenciais terem sido, abruptamente, substituídas por aulas remotas e essa atividade passou a ser realizada também por professores e por monitores (alunos) selecionados para auxiliarem os professores nas atividades docentes no ensino remoto, semi-presencial ou totalmente online

Palavras-chave: EAD, Tutor online, Mediação pedagógica.

\section{ABSTRACT}

This study presents the results of a qualitative research on pedagogical factors involved in mediating the tutor : the case of the Bachelor in Public Administration Distance ( ADMP) of PNAP offered through the UAB in a public university in northeastern Brazil System, initiated in 2009 and was motivated by question: There are factors that influence the mediation of the online tutor ? Their goal was to identify factorsthat affect the mediation of online tutor. To collect data, a questionnaire was administered and conducted an interview with the online tutors. Messages posted to the Virtual Learning Environment (VLE ) were also observed. Participated in the survey, 11 tutors online that was presents in the course researched, between 2012 and 2013 The research result indicates that the factors related to the quality of education; the quality ofinstructional materials and learner support materials; the quality of AVA; physical, technological and administrative available to students and the degree of approximation between the teacher and tutor; infrastructure interfere with the performance of the online tutor who works in the process: teaching - study - learning the of virtual student. It should be noted that the content of this article was discussed on several occasions in 2014 and 2015. However, it is relevant to resume the discussion in the field of DE due to the pandemic moment, in which the pedagogical mediation was intensified, due to the fact that the in-person classes were, abruptly, replaced by remote classes and this activity began to be performed also by teachers and monitors (students) selected to assist teachers in teaching activities in remote, semi-present or fully online teaching.

Keywords: EAD, Online tutor, pedagogical mediation.

\section{O TUTOR ONLINE DE CURSOS ACADÊMICOS E A MEDIAÇÃO PEDAGÓGICA}

Para Mill (2007) o desenvolvimento da EAD implica na necessidade de ampliar a visão sobre o papel dos profissionais que exercem o trabalho docente que semodifica a cada dia.

A relação ensino-aprendizagem nesse contexto conta, por exemplo, com o docente-tutor. Entre as denominações atribuídas a este docente percebemos tutor virtual, tutor eletrônico, mentor, tutor presencial, tutor de sala de aula, tutor local, orientador acadêmico, animador e diversas outras. $\mathrm{O}$ que caracteriza este trabalhador é sua função de acompanhar os alunos no processo de aprendizagem, que se dá, na verdade, pela intensa mediação tecnológica. Justamente por ser um novo parceiro na construção do conhecimento e pela falta de práticas 
e modelos educacionais aos quais pudemos ter acesso, o trabalho do tutor requer atenção e cuidado de toda a equipe envolvida em EaD. (MILL, 2007, p.113)

Para padronizar as atividades realizadas por esse profissional a Coordenação de Aperfeiçoamento de Pessoal de Nível Superior (CAPES)/Universidade Aberta do Brasil (UAB) estabeleceu de forma detalhada as atribuições do tutor, quais sejam:

\footnotetext{
$\checkmark$ Mediar a comunicação de conteúdos entre o professor e os estudantes;

$\checkmark$ Acompanhar as atividades discentes, conforme o cronograma do curso;

$\checkmark$ Apoiar o professor da disciplina no desenvolvimento das atividades docentes;

$\checkmark$ Manter regularidade de acesso ao Ambiente Virtual de Aprendizagem - AVA e responder às solicitações dos alunos no prazo máximo de 24 horas;

$\checkmark$ Estabelecer contato permanente com os alunos e mediar as atividades discentes;

$\checkmark$ Colaborar com a coordenação do curso na avaliação dos estudantes;

$\checkmark$ Participar das atividades de capacitação e atualização promovidas pelainstituição de ensino;

$\checkmark$ Elaborar relatórios mensais de acompanhamento dos alunos eencaminhar à coordenação de tutoria;

$\checkmark$ Participar do processo de avaliação da disciplina sob orientação doprofessor responsável.
}

De acordo com Tébar (2011), o tutor online, atualmente, vê-se desafiado em seu cotidiano, necessitando da automodificação, tanto pessoal como profissional, recorrendo aos conceitos freudianos de autoplasticidade "flexibilidade, controle das próprias emoções e sentimentos, mudança na visão que se possui de um problema ou situação" (tébar 2011, p. 241) e aloplasticidade “contextualização, adaptação das circunstâncias que permitam alcançar, da melhor forma possível, determinados objetivos" (op. cit, p. 242).

Tébar (2011), afirma ainda que a mudança é uma condição vital para a adaptação do ser humano a cada dia, e que no caso da mediação do tutor online essa exigência torna-se mais acentuada devido à necessidade de ele assumir a postura de sujeito inovador, com competência, habilidade, capacidade de administração do tempo, com inteligência emocional, empatia e relação de proximidade com o professor, para que o processo de ensino-estudo-aprendizagem ocorra satisfatoriamente, tendo como foco o aluno online bem-sucedido em suas produções acadêmicas.

Com o surgimento da pandemia da COVID 19 que exigiu o afastamento social, o tutor necessitou usar de todas as ferramentas disponíveis para conseguir realizar a mediação pedagógica e as interações de modo geral com os alunos para manter a comunicação presente. A partir de 2020, foram inseridos recursos didáticos para a realização das atividades da tutoria, como: telefone, whatsapp, instagram, google meet, e até o facebook que no Brasil, já estava em desuso por muitos, foi resgatado. OLIVEIRA, et al (2021 p. 2453) ratifica quando afirma que "cultura do conhecimento, os laços sociais de forma antiga estão diminuindo com o avanço tecnológico e novas formas de se comunicar estão surgindo com as novas mídias de interação social e educacional”. 
Miranda 2021, chamou a atenção sobre a importância da motivação dos alunos durante a mediação pedagógica no ambiente virtual de aprendizagem, conforme exposto a seguir:

\begin{abstract}
Mediar a aprendizagem no ambiente virtual de aprendizagem na dimensão atitudinal se reveste de uma ação motivacional em que o tutor a distância procura despertar no educando o desejo de aprender, de estudar, de cursar a disciplina, de continuar no curso. Essa motivação contribui para que a solidão virtual seja desarticulada e o educando possa sentir o sinal de pertencimento e venha interagir com o tutor a distância, com os colegas do curso com a ferramenta, com o material didático na construção do conhecimento da disciplina que está cursando. MIRANDA (2021 p. 1950)
\end{abstract}

$\mathrm{Na}$ época que a pesquisa foi realizada presumiu-se que seria interessante pesquisar e discutir a temática. Na situação atual, na qual vivemos o momento que a pandemia assolou o mundo todo e a EAD passou a fazer parte da vida de todos os estudantes, em particular os alunos dos cursos universitários, consideramos que as pesquisas sobre fatores intervenientes na mediação pedagógicas passaram a ter nova importância, uma vez que todos os envolvidos com a EAD estão sofrendo impacto desse momento e necessitam conviver e superar para que a educação não sofra o colapso do abodono/evasão escolar.

\title{
2 CONTEXTO METODOLÓGICO
}

O estudo se reporta a um recorte de dissertação de mestrado, cuja pesquisa foi realizada na $1^{\text {a }}$ turma do curso ADMP/PNAP/UAB, de uma instituição pública de ensino superior, do Brasil, que iniciou suas atividades em 2009, o qual contou com a mediação pedagógica de 17 tutores que atuaram em polos instalados em quatro municípios do Estado onde a pesquisa foi realizada, dos quais 11 participaram da pesquisa objeto deste estudo e teve como objetivo identificar os fatores intervenientes e as múltiplas determinações que interferem na mediação pedagógica do tutor.

Da amostra de 11 participantes e de acordo com perfil disponível no AVA/MOODLE, e das respostas do questionário, foram obtidos os seguintes dados sobre eles: (a) gênero: quatro são do gênero masculino e sete são do gênero feminino. (b) idade: a maioria dos tutores que responderam têm idades que variam entre 22 a 40 anos; (c) escolaridade graduação: quatro tutores são graduados em Administração, dois em Pedagogia, três em Ciências Econômicas, um em Economia, um em Ciências Contábeis, um em Direito, um em Comunicação Social e um cursando Sistema da Informação. Todos tem, pelo menos, uma especialização concluída: dois em Gestão do Desenvolvimento Universitário, um em EAD, um em Gestão Financeira Controladoria e Auditoria, um em Direito processual, três em Gestão Pública, um em Gestão Pública e Gerência de Cidades, um em Gestão Estratégia de Empresas e Marketing, um com mestrado concluído em Economia Aplicada e um mestrado em andamento em Educação Brasileira na linha das TIC. 
Os quantitativos de graduações e especializações apresentam-se em número maior do que o número de pesquisados, tendo em vista que alguns possuem mais de uma graduação ou pósgraduação.

A metodologia utilizada na pesquisa foi o estudo de caso com abordagem qualitativa tanto na coleta de dados, como na apresentação e análise dos resultados.

De acordo com Minayo e Sanches (1993, p. 244) que afirmam que a abordagem qualitativa realiza uma aproximação fundamental e de intimidade entre sujeito e objeto, uma vez que ambos são da mesma natureza: ela se envolve com empatia aos motivos, às intenções, aos projetos dos atores, a partir dos quais as ações, as estruturas e as relações tornam-se significativas.

Para (MINAYO, 2012, p.148), “a metodologia é o caminho do pensamento e a prática exercida na abordagem da realidade”. Para a autora a metodologia é um conjunto de técnicas que serão responsáveis para a construção da realidade através de instrumentos claro, coerente e bem elaborado. Será utilizada de acordo com o tipo de pesquisa no projeto científico. Exemplo: pesquisa de campo, revisão de literatura, revisão integrativa e estudo de caso.

Os dados da pesquisa foram organizados, categorizados e analisados com base na Teoria da Análise de Conteúdo, proposta por Bardin (2011), privilegiando duas fases propostas pelos autores:

$1^{\text {a }}$ Fase - Pré-análise

$2^{\mathrm{a}}$ Fase - Exploração do material e categorização

A Figura 1 apresenta a categorizações realizadas para o tema pesquisado:

Figura 1 - Mediação pedagógica e subcategorias

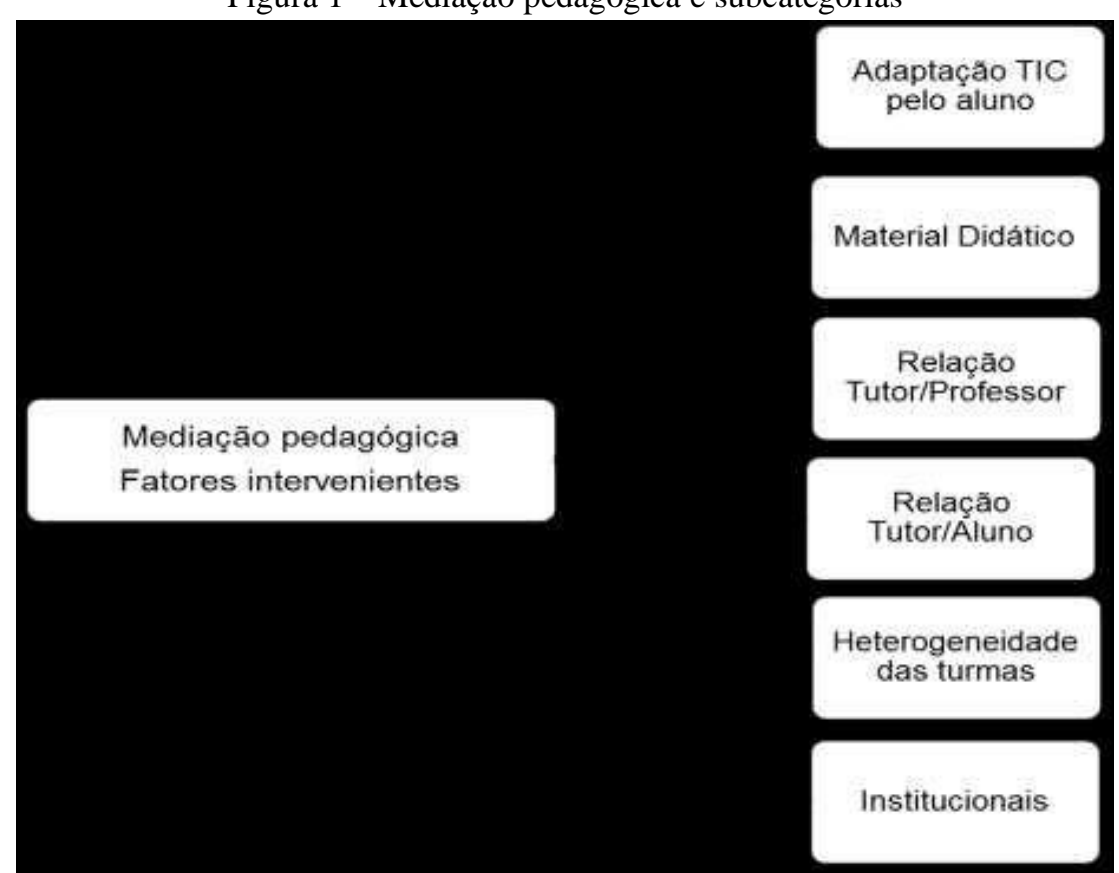

Fonte: Fonte: LIMA (2015) 
As respostas dos participantes da pesquisa foram identificadas pelos símbolos constantes no Quadro 1, de acordo com o respectivo instrumento utilizado (questionário, observação no AVA ou entrevista).

\begin{tabular}{|l|l|}
\hline \multicolumn{2}{|c|}{ Quadro 1 - Identificação do instrumento de pesquisa usado na coleta de dados. } \\
\hline Símbolo & $\begin{array}{l}\text { Descrição } \\
\text { quecortion refio. }\end{array}$ \\
\hline
\end{tabular}

Fonte: LIMA (2015)

Para preservação da identidade dos participantes, os tutores foram identificados coma letra T e receberam uma numeração conforme a ordem da entrevista. Por exemplo: T1, T2 e assim sucessivamente.

\section{RESULTADOS DOS DADOS COLETADOS REFERENTES A FATORES INTERVENIENTES DAMEDIAÇÃO PEDAGÓGICA DO TUTOR}

\subsection{ADAPTAÇÃO DAS TIC PELOS ALUNOS}

Para os respondentes, parte dos alunos inicia o curso sem a devida preparação paraestudar a distância com uso da informática e da internet. Detectou-se também que alguns alunos se mantêm no curso realizando as atividades com ajuda de terceiros e solicitando constante atenção do tutor para orientá-los, mesmo a distância, para resolver questões simples.

T10 [...] tem alunos que realmente têm dificuldade até de postar documentos no Word devido à dificuldade de digitação, formatação do texto;então, as dificuldades existem.

T8 [...] Às vezes eles entram e não conseguem achar onde fica o fórum. Nem sempre são alunos com contato com essa questão da informática [...]

\subsection{MATERIAL DIDÁTICO}

As respostas revelaram o material didático é indispensável para a mediação do tutor com os alunos, visto que é ele um dos elementos que promove a produção acadêmica dos alunos e também 
pelo fato de, além do aluno, ele envolver o tutor, o professor e o AVA, simultaneamente. No entanto, às vezes ele chega tardiamente, afetando negativamente o trabalho do tutor:

T9 [...] O material didático [...] teria que chegar mais cedo... é.... bem antes para o tutor, antes do início do início da disciplina. Ele chega quase junto com o aluno. Também, seria bom que tivesse mais texto ou outro material no AVA para o tutor. E que fosse dado mais tempo para o tutor visualizar as próximas semanas no AVA. Às vezes o tutor visualiza junto com os alunos [...].

T8 [...] O sucesso da disciplina vai depender de o material ser passado, antecipadamente para o tutor ter aquela prévia $[\ldots]$

Os dados também revelaram que a falta do material didático ou a entrega dele, depois do início das aulas pode contribuir para a falta de domínio do conteúdo da disciplina pelo tutor e comprometer o entendimento das atividades solicitadas aosalunos. E ainda pode denegrir a imagem do trabalho do tutor, já que ele não vai ter precisão nas respostas a serem dadas aos alunos.

Entre as respostas obtidas no questionário e nas entrevistas com os tutores, oplano de tutoria foi destacado, sob a observação da sua importância como instrumento de orientação para o tutor realizar a mediação pedagógica em conformidade com as expectativas do professor autor da disciplina. Nos resultados também foi visto que o tutor sente falta de um padrão de resposta para corrigir as atividades dos alunos.

[...] a ausência do plano de tutoria ou existência de planos incompletos ou incompreensíveis pelo tutor comprometem a mediação pedagógica do tutor com os alunos $[\ldots]$

T5 [...] No meu caso, é até melhor olhar o Guia de Estudos do Aluno doque o plano de tutoria, porque o guia de estudos é uma coisa mais detalhada [...] às vezes a gente leva mais tempo estudando, pesquisando, pra poder dar uma resposta coerente, até porque o professor faz o material, elabora todas as atividades, mas não dá padrão de resposta pra gente [...]

Com relação à relevância de plano de tutoria, analisando os dados do questionário, 10 tutores pesquisados responderam que o plano é indispensável e apenas um, afirmou que é dispensável fazendo paradoxo às demais respostas.

\section{O plano de tutoria é indispensável - É essa possibilidade de maior}

entrosamento entre professores e tutores que passa pela descrição das expectativas do professor, maior e último responsável pela disciplina, pode se expressar no plano, já que ali o professor orienta, capacita, dá um rumo eaté pode impor certa "velocidade" que deseja ver no curso. O plano é mais um guia, se bem feito, ele deixa claro os "porquês", "como" e "quando", dando um significado especial pra atuação dos tutores; 
Ainda sobre o material didático, observou-se que a quantidade excessiva de atividades e/ou conteúdos compromete significativamente a mediação pedagógicado tutor, visto que demanda maior quantidade de tempo para realizar a leitura de todo o conteúdo da disciplina, para só depois corrigir, comentar as postagens dos alunos e atribuir as notas dentro de critérios que nem sempre vêm explícitos no material didático entregue pelo professor:

[...] Quantidade excessiva de atividades, por disciplina compromete a mediação pedagógica $[\ldots]$

T7 [...] houve disciplina em que um(a) professor(a) colocou pra uma semana mais de 40 questões, entre questões abertas e fechadas [...]

Outra dificuldade apresentada nos resultados dos dados foi a ausência de material de apoio impresso ou no formato digital que possibilite a impressão, já que nem sempre o tutor está com acessibilidade às TIC e à internet, e às vezes opta por usar o material impresso, para depois realizar a mediação pedagógica no AVA.

De modo geral, de acordo com o resultado da pesquisa, o material contribuiu parcialmente para que a mediação pedagógica ocorresse de forma satisfatória no curso pesquisado, considerando que houve algumas falhas referentes à inexistência ou à qualidade do material didático específico para o tutor (conteúdo das disciplinas, slides, plano de tutoria, planilha de notas, padrão de respostas das atividades destinadas ao aluno, cronograma da disciplina, orientação para uso de ferramentas não conhecidas totalmente pelo tutor, contatos do professor e do suporte tecnológicopara esclarecimento de dúvida, etc.); à demora da entrega do material didático ao tutor ou à disponibilidade no AVA de forma inadequada; ou referente à quantidadede conteúdo ou de atividades para a correção do tutor e atribuição de notas aos alunos.

\subsection{RELAÇÃO TUTOR/PROFESSOR}

O resultado da pesquisa revelou que uma das grandes dificuldades do tutor para realizar a mediação pedagógica com os alunos foi a falta de entrosamento com os professores das disciplinas, tanto presencialmente como no AVA. Sobre essa temática, durante a análise dos dados observou-se que, aparentemente, o professor não reconhece que a presença dele no AVA seja tão importante e necessária.

Falta de interação Professor e tutor para exploração do conteúdo, exposição das expectativas e esclarecimento de dúvidas desde a ementado curso até a avaliação final da disciplina. 
T4 [...] Se o professor não deixa bem claro aonde ele quer chegar, fica difícil pra o tutor que não é dono do conteúdo, que não foi responsável pelo conteúdo, conduzir, porque ele não sabe. Não foi ele que criou, elaborou o conteúdo que os alunos estão seguindo (estudando). Ele é apenas um mediador [...]

T6 [...] Com relação ao professor, aqueles que são abertos, que atendem a gente, é ótimo, mas, do meu tempo de experiências, tem alguns que são assim.... como eu posso dizer... são... fechados, entendeu? E isso dificulta um pouco o trabalho da gente.

T4 [...] Tem professor que é show de bola. Prepara tudo direitinho, bem didático, detalha cada passo, e aí a gente consegue chegar ao objetivo [...]

Analisando as respostas, percebe-se que o tutor almeja que o professor trabalhe de forma conjunta e integrada com ele; anseia por manter uma proximidade presencial ou mesmo por outros meios de comunicação como e-mail, telefone, etc., para tirar as dúvidas sobre algum ponto do conteúdo que porventura tenha ficado obscuro para ele, esclarecimentos sobre os critérios de correção, discussão sobre a atribuição das notas e exposição das expectativas de ambos.

Os tutores citam a capacitação como sendo um dos poucos momentos de aproximação e interação com o professor, mas descrevem a capacitação como algo que fosse um rápido encontro (reunião), no qual o professor entrega o material, conversa um pouco com os tutores e os deixam sozinhos para atuar na disciplina com o aluno. Essa ocorrência também pode ser considerada uma oportunidade para a coordenação promover aproximação do professor com o tutor, visando ampliar o intercâmbio entre ambos, almejando que a mediação pedagógica ocorra sempre com a excelência desejada.

\subsection{RELAÇÃO TUTOR/ALUNO}

De acordo com o resultado da pesquisa, uma das dificuldades do tutor para realizara mediação pedagógica está na relação com o próprio aluno, tendo em vista que o tutor poderá se deparar com situações que podem comprometer a produção acadêmica do aluno, como:

Falta de administração do tempo por parte do aluno:

T8 [...] A maioria deles não sabe gerenciar o tempo. A gente percebe noenvio das atividades e nos fóruns. Eles mandam no último dia [...].

Alunos que priorizam disciplinas ou outras questões pessoais ou profissionais em detrimento da realização dos estudos e das atividades acadêmicas 
T5 [...] O aluno não está respeitando a carga horária do curso que seria para o estudo dele. É tipo assim: isso não é a prioridade na vida da maioria dos alunos, porque quando a gente manda uma mensagem, perguntando por que a atividade não foi postada, por que não comentou no fórum, eles respondem dizendo assim: é porque eu estou sem tempo, não porque estava fazendo essas outras atividades [...]

T9 [...] Eu percebo que eles ...vão priorizando disciplina. Eles concluem uma disciplina, aí é reprovado em outra, entende? [...]

Dificuldade do tutor para motivar os alunos a interagirem nos fóruns dediscussão do conteúdo da disciplina:

T4 [...] Outra dificuldade é a interação com o próprio aluno. Muitas vezes você não consegue fazê-lo participar da disciplina. Às vezes o aluno está participando só pra obter aquela nota. Eles esquecem que o mais importante é o que ele aprendeu com aquela atividade, com aquela participação naquele fórum. [...] você joga uma pergunta num fórum pra verse ele continua interagindo, mas ele nem liga mais, porque ele acha que o que já fez já foi suficiente, nem olha as demais postagens dos colegas para poder linkar e fazer algum comentário.

T5 [...] a gente manda mensagem perguntando por que eles (alunos) não acessam. É como se eles fizessem o curso no tempinho que eles tivessem disponível. No tempinho. Mas a gente sabe que você não faz um curso de graduação num tempinho [...]

$\checkmark$ Dificuldade do tutor para lidar com a questão do plágio "publicamente" postadonos fóruns de aprendizagem.

T5 [...] Muitas vezes ele pega o tema do fórum, joga na internet, copia ecola lá pra mostrar que ele participou. [...]

\subsection{HETEROGENEIDADE DAS TURMAS}

Pelas respostas dos tutores constatou-se a existência de turmas heterogêneas com características diversificadas: domiciliados na zona rural ou zona urbana, com acessibilidades às TIC e à internet ou não, pessoas nascidas na era digital ou pessoas conectadas mais recentemente, e pessoas que necessitam de apoio para realizar as tarefas.

Analisando o contexto em que o tutor realiza a mediação pedagógica com os alunos, considerando a heterogeneidade da turma, acredita-se que realmente não seja fácil, para o tutor, lidar com um público com perfis e características tão diversificadas, com estilos de vida tão variados, que vivem em ambientes tão diferentes uns dos outros (zona rural, zona urbana), com acessibilidades às TIC e à internet de formas variadas, com pessoas nascidas na era digital ou pessoas conectadas e pessoas que necessitam de apoio e orientação pormenorizada para realizar as tarefas, ou que recorram a terceiros para ajudá-las no cotidiano educacional. 
T10 [...] nós temos alunos, de graduação, pós-graduação e alunos que estão iniciando agora a vida acadêmica $[\ldots]$

\section{thot}

Licenciada em História [...] Serviço Social; Administração [...] e pós-graduada em Gestão Estratégica RH; Graduando em Engenharia da Produção (EAD); Advogado; Bióloga, especialista em Ciências Ambientais; Ciências Contábeis; Primeira graduação [...]

T4 [...] Tem alunos com postura de aluno de ensino médio, de ensino fundamental, onde eu chego e digo: complete a frase. [...] No ensino a distância, não dá pra trabalhar dessa forma.

T10 [...] na grande maioria trabalham e têm família, e isso dificulta os alunos e acabam priorizando outras atividades ou priorizando outras disciplinas que estejam em mais dificuldades e talvez amenizando em outras. [...]

Os dados indicam a necessidade das IES, em especial aquelas que ofertam curso de EAD via internet, refletirem sobre como preparar o tutor para lidar com essadiversidade e como orientar os alunos de cursos online para que a comunicaçãoseja efetivada no AVA do curso apresentando. Essa comunicação deve apresentar precisão, clareza e objetividade, sem transgredir os valores históricos, políticos, culturais, religiosos, entre outros, para que as mensagens cheguem aos seus receptores com imparcialidade e assertividade. Bem como motivar os alunos para realizar as atividades, mesmo nas ocasiões nas quais os problemas pessoais ou profissionais aflorarem e concorrerem com as atividades acadêmicas.

\subsection{AVA}

Um dos fatores citado pelos tutores com destaque para: (a) organização dos tópicos e da disciplina; (b) imperfeição na funcionalidade dos acessos no ambiente referentes a cada atividade; (c) instabilidade de acesso ao AVA, entre outros.

Organização dos tópicos e tarefas da disciplina de forma inadequada

T10 [...] Com relação ao AVA [...] no ambiente, nós temos duas ferramentas que são praticamente mais utilizadas. São as únicas, praticamente. São o envio das atividades através do link e a participaçãodos fóruns. [...] Tem se tentado uma terceira alternativa, mas não tem obtido sucesso, que é o chat, que é uma oportunidade em que o aluno pode conversar com o professor conversar com o tutor online dentro daquela programação que o professor estabelece. Foram feitas algumas tentativas, mas nunca ocorreu como deveria [...]

T6 [...] Eu acho que a ferramenta do Moodle deveria ser trabalhada de forma melhor, porque ele é muito frio, pouco atrativo. O Moodle do jeito que ele tá hoje para o curso ele está muito estático, parado. Eu acho que isso não motiva tanto o aluno [...]

Com relação à organização dos tópicos e da disciplina, as respostas dos tutores mostram que o ambiente não se apresenta atraente, nem bem distribuído em todas as disciplinas. Mas acredita-se 
que aos poucos a IES analisada perceba a necessidade de alterações e identifique os prováveis locais que sofrerão as intervenções do designer instrucional:

Imperfeição na funcionalidade dos acessos no ambiente referentes a cada atividade

T5 [...] Uma coisa que a gente sempre fala é a funcionalidade do AVA. Tem chat lá que desde o começo do curso foi tentado, mas ele não funciona. Alguns professores já tentaram, mas não deu certo. Seria como se fosse um fórum instantâneo, aquele chat seria assim: o professor tava ali a disposição para realizar a discussão e seria interessante porque a gente nota que quando o professor entra na plataforma, o aluno se estimula mais a participar, porque parece que ele pensa: "eita, o professor está me vendo". Eu acho que isso seria uma contribuição positiva.

Os dados também indicaram que na visão da maioria dos tutores respondentes, nem sempre o problema está, exatamente no AVA. Às vezes está na falta de domínio do usuário desse espaço virtual. Por exemplo: quando existe uma ocorrência inesperada, é possível que reclamações indevidas sejam configuradas e que o problema possa ser atribuído ao AVA.

\subsection{ESTRUTURA PEDAGÓGICA}

Uma das dificuldades apontadas pelo tutor é quando existem mais de 25 alunos por turma. Não é apenas o quantitativo em si que vai estabelecer o volume de trabalho e o tempo gasto para o tutor realizar a sua atividade didática, e sim todo contexto no qual as mediações são realizadas, visto que, além do retorno crítico relacionado ao conteúdo da disciplina, são inseridos outros elementos como AVA, a heterogeneidade dos alunos, questões pessoais do tutor (doença), falta de energia, etc.

Durante a pesquisa não foi percebida dentro da estrutura pedagógica, a existência de contingência de pessoal para suprir eventuais ausências do tutor, nem serviço de apoio ao tutor em caso de sobrecarga de trabalho motivada por fatores externos ao processo ensino-aprendizagem em casos de turmas com mais de 25 alunos.

Mais de 25 alunos por turma compromete a mediação pedagógica dotutor

T7 [...] E a gente que é tutor, tem que dar o feedback de 25 a 50 alunosnuma semana com tempo de 24 horas, [...] e tem que comentar cada uma delas. Eu não posso dizer: não fez, não fez, não fez.

\subsection{ESTRUTURA ADMINISTRATIVA}

Os dados revelaram também que quando não existe uma alternativa para os alunos cursarem disciplinas em que foram reprovados, isso leva esses alunos a ficar fora da sala de aula por muito tempo aguardando uma nova turma ser ofertada. Ao retornar para concluir o curso, o tutor precisa dar 
atenção adicional para a reinserção numa turma de novos alunos, o que exige um período de readaptação. Na visão dos tutores, isso afeta a mediação pedagógica:

T10 [...] alunos de turmas anteriores possam pagar disciplinas, pois nem todos alunos conseguem aprovação em todas as disciplinas, e para que não fiquem com um intervalo de tempo de dois ou três anos esperando oportunidade para concluir o curso, e só com a chegada de novas turmas osalunos podem concluir as disciplinas [...]

$\mathrm{Na}$ pesquisa, foram encontrados dados que mostram situações inusitadas, as quais podem afetar a mediação pedagógica do tutor com os alunos, se não houver a sintonia e o entrosamento entre o professor, coordenação e tutor, uma vez que

ocorrências como a citada a seguir podem comprometer o cumprimento dos prazos do calendário e provocar conflitos ou descontentamentos, e, sobretudo, se houver falha na comunicação sobre alterações das datas referentes às postagens, entrega de atividades ou agendamento para o novo encontro presencial a fim de repor o que foi cancelado. A situação poderá se agravar mais ainda e gerar novas demandas de trabalho para o tutor, que poderá precisar incluir novas interações com os envolvidos, até a completa solução do problema.

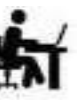

[...] devido a dificuldades na operacionalização dos transportes parao interior, sinto informar que as atividades presenciais deste fim de semana (7 de dezembro) das matérias da reoferta estão canceladas [...]

Os resultados também sinalizam que existem novos espaços para investigações que merecem ser desenvolvidas, a fim de indicar o estabelecimento de processos didáticos com mediação pedagógica via tecnologias, capazes de produzir, nos alunos, melhor condição cognitiva, de atitudes e de aquisição de habilidades para a aprendizagem, desde que as postagens dos tutores sejam para além de uma simples confirmação de recebimento, de estímulo para a realizaçãodas atividades, e com uma efetiva mediação pedagógica com o retorno crítico ao aluno.

\section{CONSIDERAÇÕES FINAIS}

O resultado da pesquisa indica que durante a mediação pedagógica, o tutor depara-se com fatores intervenientes que interferem no desempenho dele que atua diretamente com o aluno no processo de ensino-estudo-aprendizagem nas ofertas de curso EAD online.

No entanto, mesmo que o tutor trabalhe em condições não favoráveis (infraestrutura física, pedagógica, tecnológica e disponibilidade de tempo) para realizar a mediação pedagógica com o aluno, supõe-se que os fatores intervenienteselencados nesta pesquisa possam vir a ser superados a 
depender da atuação do tutor para que o aluno não seja afetado tão negativamente no que se refere a essa mediação, em especial no retorno crítico das atividades; revelando que as múltiplas determinações poderão ocorrer em pró ou não de uma formação de qualidade. Tudo dependerá da sinergia que se estabeleça entre atores e agentes deste complexo processo.

Neste sentido, almeja-se que o resultado deste estudo venha contribuir para a promoção de debates sobre a situação em que o tutor se expõe quando está na sala de aula virtual e nos momentos presenciais (para os tutores presenciais) e também, sobre como os fatores intervenientes podem ser trabalhados para não comprometer sua atuação. Não fizeram parte da pesquisa, mas consideramos importante destacar, aqui, a necessidade de se discutir também a inclusão de pessoas com deficiência auditiva e visual na EAD. Na situação atual da pandemia, provavelmente exigiria do tutor outras demandas e com elas outros fatores intervenientes relacionados ao atendimento a essas pessoas com necessidades especiais de comunicação por conta das suas limitações.

Espera-se ainda que as discussões resultem em ações que venham a repercutir positivamente na satisfação do aluno, durante a realização das suas atividades acadêmicas, tendo como base o que é estabelecido pela CAPES para a realização de cursos ofertados pelo sistema UAB (Brasil) e pela Lei de Diretrizes e Bases (LDB) no 9.394/1996 em seus artigos 80 e 81. Convém mencionar que a LDB $\mathrm{n}^{\circ}$ 9.394/1996 foi atualizada em 2020 por meio da medida provisória 934 , de $1^{\circ}$ de abril de 2020 e em 2021 por meio da Lei 14.191 de 03 de agosto de 2021. Esta última, altera a LDB nº 9.394/1996 para dispor sobre a modalidade de educação bilíngue de surdos de forma mais detalhada.

Também, espera-se que as discussões motivem novas ações e que nelas sejam inseridas as possibilidades do uso das tecnologias digitais em favor das práticas docentes nos cursos superiores online, nos quais a mediação pedagógica do tutor depende das características e disponibilidade: dos alunos, dos professores, do material didático, do AVA e do contexto, no qual o processo ensinoestudo- aprendizagem esteja sendo realizado, o que exige total adequação visto que falhas em qualquer um desses elementos referenciados poderão desencadear em evasão de alunos ou implicar em imagem negativa da atuação do tutor, bem como da instituição que está ofertando o curso. 


\section{REFERÊNCIAS}

BARDIN, Laurence. Análise de Conteúdo; Tradução: Luiz Antero Reto, Augusto Pinheiro. São Paulo: Edições 70. 2011. Tradução de: L'analyse de contenu.

BRASIL. Lei n ${ }^{\circ}$ 9.394, de 20 de dezembro de 1996 Estabelece as diretrizes e bases da educação nacional atualizada em 2020 4. ed. - Brasília, DF. Disponível em https://www2.senado.leg.br/bdsf/handle/id/572694 Acesso em: 19 ago 2021

BRASIL. Medida provisória $\mathrm{n}^{\circ} 934$ de $1^{\circ}$ de abril de 2020 que altera a Lei $\mathrm{n}^{\circ}$ 9.394, de 20 de dezembro de 1996. Brasília, DF: Congresso Nacional. Disponível em https://www.congressonacional.leg.br/materias/medidas-provisorias/-/mpv/141349 Acesso em: 20 ago 2021

BRASIL. Lei $\mathrm{n}^{\circ} 14.191$ de 03 de agosto de 2021 que altera a Lei n ${ }^{\circ}$ 9.394, de 20 de dezembro de 1996. Brasília, DF: Camara dos deputados. Disponível em https://www.in.gov.br/en/web/dou/-/lei-n-14.191de-3-de-agosto-de-2021-336083749 Acesso em: 20 ago 2021

COORDENAÇÃO DE APERFEIÇOAMENTO DE PESSOAL DE NÍVEL SUPERIOR (CAPES). Universidade Aberta do Brasil (UAB). Resolução no 26/2009-CD/FNDE Anexo I - Manual de Atribuições dos Bolsistas. Disponível em http://www.ufrgs.br/tri/sead/sead-2/legislacaoead/documentos/Resolucao\%20CD-FNDE\%2026-09\%20-\%20Anexo\%20I\%20-

\%20Manual\%20de\%20atribuicoes\%20dos\%20bolsistas.pdf/view Acesso em: 21 ago 2021

LIMA. M. A. A. A mediação pedagógica do tutor e a produção autoral do aluno: o caso de um curso do PNAP. Maceió: EDUFAL, 2015, v.01. p.158.

MILL, D. et al. O desafio de uma interação de qualidade na Educação a Distância: o tutor e sua importância nesses processos. Texto impresso, 2007 (p, 112-127). Disponível em http://www.cadernosdapedagogia.ufscar.br/index.php/cp/article/ view/106/63 Acesso em 19 de ago de 2021

MINAYO, M. C. S; SANCHES, O. Quantitative and qualitative methods: oppositionor complementarity? Cad. Saúde Públ., Rio de Janeiro, v.9, n. 3, p.239-262, jul./set. 1993.

MINAYO, Maria Cecília de Souza (org.). Pesquisa Social. Teoria, método e criatividade. 18 ed. Petrópolis: Vozes, 2012.

MIRANDA N. P. Avaliação dos saberes na mediação online na educação superior semipresencial. in Latin American Journal of Development, Curitiba, v.3, n. 4, p. 1947-1954, jul./ago. 2021. ISSN 2674-9297. Disponível em: https://latinamericanpublicacoes.com.br/ojs/index.php/jdev/article/view/435/417. Acesso em 21 de ago de 2021

OLIVEIRA C. M. et al. O impacto da autoria em rede e das produções colaborativas no processo de aprendizagem para além da transmidiação in Latin American Journal of Development, Curitiba, v.3, n. 4, p. 2452-2455, jul./ago. 2021. ISSN 2674-9297.Disponível em: https://latinamericanpublicacoes.com.br/ojs/index. php/jdev/article/view/685. Acesso em 19 de ago de 2021 
TÉBAR, L. O perfil do professor mediador: pedagogia da mediação. Tradução de Priscila Pereira Mota. São Paulo: SENAC, 2011. 